\title{
Antimicrobial Efficacy of Diclofenac Sodium Against Candida Albicans by Determining Minimal Inhibitory Concentration (Mic) and Minimal Fungicidal Concentration (Mfc) - An in Vitro Study
}

\author{
Mulumoodi Rama Sowmya ${ }^{1}$, Ajitha. $P^{2}$ and Pradeep. $S^{3}$ \\ ${ }^{1}$ Department of Conservative Dentistry and Endodontics, Saveetha Dental College, Saveetha \\ Institute of Medical and Technical Sciences,Saveetha University, Chennai 77, India. \\ ${ }^{2}$ Professor, Department of Conservative Dentistry and Endodontics, Saveetha Dental College, \\ Saveetha Institute of Medical and Technical Sciences, Saveetha University, Chennai-77, India \\ ${ }^{3}$ Reader, Department of Conservative Dentistry and Endodontics, Saveetha Dental College and hospitals, \\ Saveetha Institute of Medical and Technical Sciences, Saveetha University Chennai-77, India
}

\section{ABSTRACT}

According to some recent studies, Non steroidal anti inflammatory drugs(NSAIDs) have shown some antimicrobial activity. The aim of this study is to evaluate the antimicrobial activity of Diclofenac sodium against Candida albicans in comparison with Calcium hydroxide. The test samples consisting of diclofenac sodium (DS) 20mM/ $\mathrm{ml}$ was prepared as a stock solution at various concentrations $(0.5,2.5,5.0,7.5$ and $10.0 \mathrm{mM} / \mathrm{ml})$ of the working solution was prepared for Minimal Inhibitory Concentration (MIC) and Minimal Fungicidal Concentration (MFC) assay. $\mathrm{Ca}(\mathrm{OH}) 21.75 \mathrm{mg} / \mathrm{ml}$ was used as positive control. Fungal strains (Candida albicans) (ATCC 10231) were chosen based on their clinical and pharmacological importance. The fungal stock cultures were incubated for 24 hours at $37^{\circ} \mathrm{C}$ on potato dextrose agar (PDA) medium, following low temperature storage at $4^{\circ} \mathrm{C}$. The fungal strains were grown in Sabouraud dextrose agar and PDA media, respectively, at $28^{\circ} \mathrm{C}$. The stock cultures were maintained at $4^{\circ} \mathrm{C}$. On analysing the MIC, all the test groups showed significant differences when compared to the negative control group $(\mathrm{p}<0.01)$, no significant difference seen between Diclofenac sodium $(10 \mathrm{mM} / \mathrm{ml})$ and calcium hydroxide group ( $>0.05)$. On analysing the MFC,no significant difference is seen between Diclofenac sodium $(7.5 \mathrm{mM} / \mathrm{ml})$ to Diclofenac sodium $(10 \mathrm{mM} / \mathrm{ml})(\mathrm{p}>0.05)$. Within the limitations of the study, it has been noticed that diclofenac sodium has some fungicidal activity but less when compared to calcium hydroxide.

KEY WORDS: CANDIDA ALBICANS; CALCIUM HYDROXIDE; DICLOFENAC SODIUM; MINIMAL INHIBITORY CONCENTRATION (MIC); MINIMAL FUNGICIDAL CONCENTRATION (MFC).

\section{ARTICLE INFORMATION}

*Corresponding Author: prasadjoness.ece@krct.ac.in

Received 14th June 2020 Accepted after revision 4th August 2020

Print ISSN: 0974-6455 Online ISSN: 2321-4007 CODEN: BBRCBA

Thomson Reuters ISI Web of Science Clarivate Analytics USA and Crossref Indexed Journal

$$
\text { 1) Clarivate }{ }_{\text {Analytics }}
$$

NAAS Journal Score 2020 (4.31) SJIF: 2020 (7.728)

A Society of Science and Nature Publication,

Bhopal India 2020. All rights reserved.

Online Contents Available at: http//www.bbrc.in/

Doi: $h$ ttp://dx.doi.org/10.21786/bbrc/13.7/38

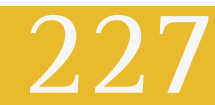




\section{INTRODUCTION}

Micro organisms play a key role in the development of pulpal and periapical diseases. Hence it is important to eliminate these bacteria by using certain local or systemic antimicrobial agents along with root canal therapy. The main aim of root canal therapy is to remove the necrosed pulp tissue, deceased bacteria, disinfect the canal and placement of intracanal medicament (Narayanan and Vaishnavi, 2010). The cleaning and shaping of the canal makes sure that most of the bacteria are eliminated. But the complex anatomy of the pulpo-dental system will allow either multiplication or recolonization of microorganisms (Young et al., 2007) Hence the placement of intracanal medicament will minimize the colonization of microorganisms. As it has a fluid consistency, it can penetrate into the inaccessible areas of canals where usual filing is not possible (Blanscet et al., 2008).

The rationale behind placing intracanal medicament is to eliminate the microorganisms and make the canal inert. This ensures that the canal is free of any possible bacteria or any other microorganisms, no weeping canals and no drainage. This makes the canal ready for obturation (Blanscet et al., 2008). The most commonly used intracanal medicament is calcium hydroxide based. This is most commonly used because of its ability to dissolve the necrotic tissue, viability in weeping canals and biocompatibility (Kim and Kim, 2014). But there are also certain potential limitations of calcium hydroxide as an intracanal medicament. These include the following:It might inhibit or delay the setting of zinc oxide eugenol sealer.Calcium hydroxide is not totally very effective against E.faecalis and Candida albicans (Kim and Kim, 2015).The precise concentration of calcium hydroxide at which it is effective against microbes is clearly not known (Blanscet et al., 2008).

Antibiotics have also been used for this purpose. However, extensive use of antibiotics led to antibiotic resistance. Hence keeping these limitations in mind, there have been studies going on for newer intracanal medicaments. NSAIDs are usually anti-inflammatory and analgesic in nature. NSAIDs act by different mechanisms one of which is antibacterial effect. The conventional use of NSAIDs is analgesic action. It may possess additional properties therapeutically such as antimicrobial efficacy mediated by inhibition of bacterial DNA synthesis or impairment of membranous activity or inhibition of biofilm formation by intervening with quorum sensing (Chockattu et al., 2018) Kristiansen and Amaral coined the term 'non antibiotic.' These drugs have been used to treat non infectious diseases but they have also been known to exhibit antimicrobial efficacy (Kristiansen, 1997).

The commonly prescribed NSAIDs are Diclofenac sodium or ibuprofen. If such compounds are incorporated as intracanal medicaments the beneficial effects such as anti inflammatory action, analgesic action and potent antimicrobial efficacy (Zimmermann and Curtis, 2017) In this study, the antimicrobial efficacy of Diclofenac sodium is being tested. Diclofenac sodium is a potent non steroidal anti inflammatory drug, analgesic with very few side effects (Chockattu et al., 2018) There are several studies which proved its efficacy in reducing postoperative complications especially after the extraction of third molars. It has also been advocated after endodontic therapy to alleviate post endodontic pain (Negm, 1994; Saatchi et al., 2009) It has also shown its antibacterial efficacy against certain gram positive and gram negative bacteria and also synergistic action with other antibiotics. However its antibacterial efficacy against all endodontic pathogens by placing it within the canal has not been studied so far (Chockattu et al., 2018; Salem-Milani et al., 2013).

We have numerous highly cited publications on well designed clinical trials and lab studies (Azeem and Sureshbabu, 2018; Govindaraju et al., 2017; Janani and Sandhya, 2019; Jenarthanan and Subbarao, 2018; Khandelwal and Palanivelu, 2019; Malli Sureshbabu et al., 2019; Manohar and Sharma, 2018; Nandakumar and Nasim, 2018; Poorni et al., 2019; Rajakeerthi and Ms, 2019; Rajendran et al., 2019; Ramarao and Sathyanarayanan, 2019; Siddique, Nivedhitha, et al., 2019; Siddique, Sureshbabu, et al., 2019; Siddique and Nivedhitha, 2019; Teja et al., 2018). This has provided the right platforms for us to pursue the current study. The aim of this study is to determine the antimicrobial efficacy of Diclofenac sodium against the endodontic pathogen Candida albicans by using it as an intracanal medicament.

\section{MATERIAL AND METHODS}

Test samples: The diclofenac sodium (DS) $20 \mathrm{mM} / \mathrm{ml}$ was prepared as a stock solution and various concentrations $(0.5,2.5,5.0,7.5$ and $10.0 \mathrm{mM} / \mathrm{ml})$ of the working solution was prepared for MIC and MFC assay. $\mathrm{Ca}(\mathrm{OH}) 2$ $1.75 \mathrm{mg} / \mathrm{ml}$ was used as positive control (Figure 1).

Figure 1: Test drugs

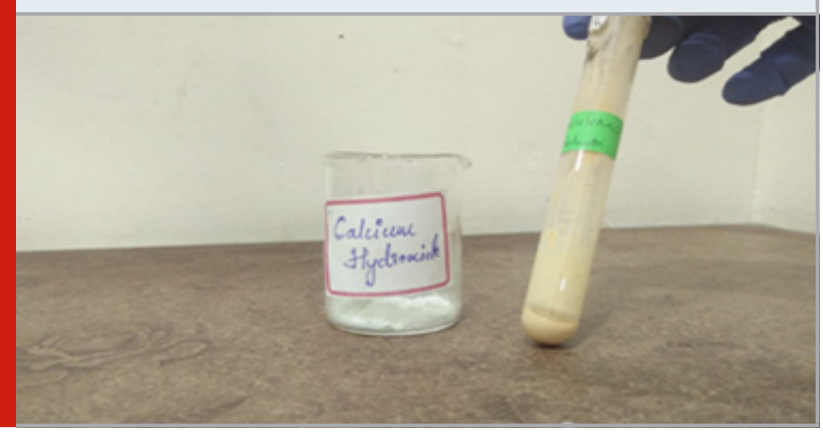

Fungal strains: Fungal strains (Candida albicans) (ATCC 10231) were chosen based on their clinical and pharmacological importance. The fungal stock cultures were incubated for 24 hours at $37^{\circ} \mathrm{C}$ on potato dextrose agar (PDA) medium, following low temperature storage at $4^{\circ} \mathrm{C}$. The fungal strains were grown in Sabouraud dextrose agar and PDA media, respectively at $28^{\circ} \mathrm{C}$. The stock cultures were maintained at $4^{\circ} \mathrm{C}$. 


\section{Determination of MIC:}

Tube dilution assay: For determining MIC, further dilutions of DS were prepared and tested at the various concentrations $(\mu \mathrm{g} / \mathrm{ml})$ on the C.albicans. The stock solutions were diluted and studied on the microorganism. Antimicrobial activity of DS was determined using the tube dilution method. MIC, is defined as the lowest concentration of a compound that has the ability to completely inhibit the microbial growth. It was determined by a standard broth dilution technique (Figure 2). The cultures were then incubated and subsequently, serially diluted to reach the density of $2 \times 104$ cells per ml. Two milliliters of MHB broth was dispensed in tubes, and 100 $\mu \mathrm{L}$ of cell culture was inoculated in it followed by 100 $\mu \mathrm{L}$ of different concentrations of DS was added to each tube. Growth control was parallelly assessed with every experimental group, for 48 hours, in an anaerobic jar all the experimental tubes were incubated. After completion of the incubation period, the optical density was measured at $600 \mathrm{~nm}$. MIC was defined as the minimum concentration of DS that caused 20\% inhibition in growth of test microorganism. Each experiment was carried out in a triplicate set. The Minimum Inhibitory Concentration (MIC) was then determined which was nothing but the lowest concentration prior to colour change.

Figure 2: Broth dilution with various conc of DS and $\mathrm{Ca}(\mathrm{OH}) 2$

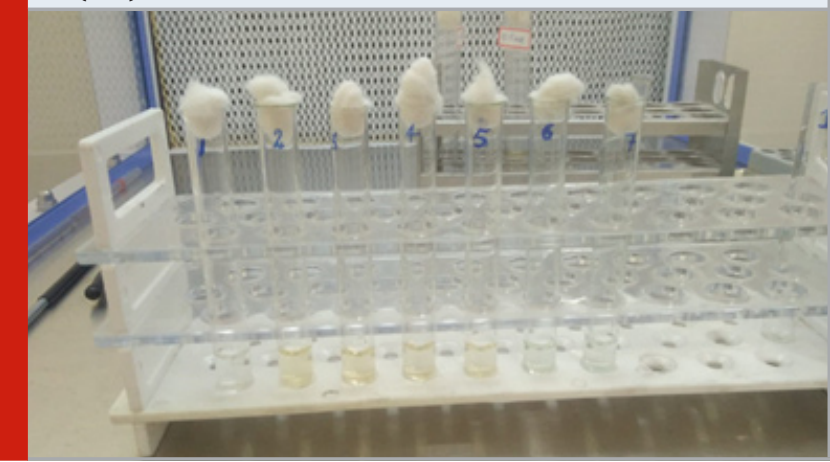

The percentage of bacterial inhibition by the test product was computed using the following equation: Percentage Inhibition $=0 D$ in control - OD in test $x 100 / 0 D$ in control

\section{Determination of MFC}

Agar well diffusion assay: Agar well diffusion assay method was applied to find out the zone of inhibition for the diclofenac sodium. C. albicans were incubated in yeast mold agar plates at $37^{\circ} \mathrm{C}$ for $24 \mathrm{~h}$ and the cultures were used to determine the zone of inhibition. The Sabouraud dextrose agar medium was poured into the petri plates and about $1 \mathrm{ml}$ of $24 \mathrm{~h}$ incubated old culture was inoculated; then the plates were set at room temperature for 10 minutes. Using a microtip the wells were made and the wells were filled with $100 \mu \mathrm{l}$ of test samples (7.5 and $10 \mathrm{mM}) . \mathrm{Ca}(\mathrm{OH}) 2$ was used as a positive control and distilled water used as negative control. All the plates were incubated at $37^{\circ} \mathrm{C}$ for 24 hours. The zone of inhibition was measured and expressed in millimetres(Figure 3). All the tests were repeated thrice.

Figure 3: Agar well diffusion assay

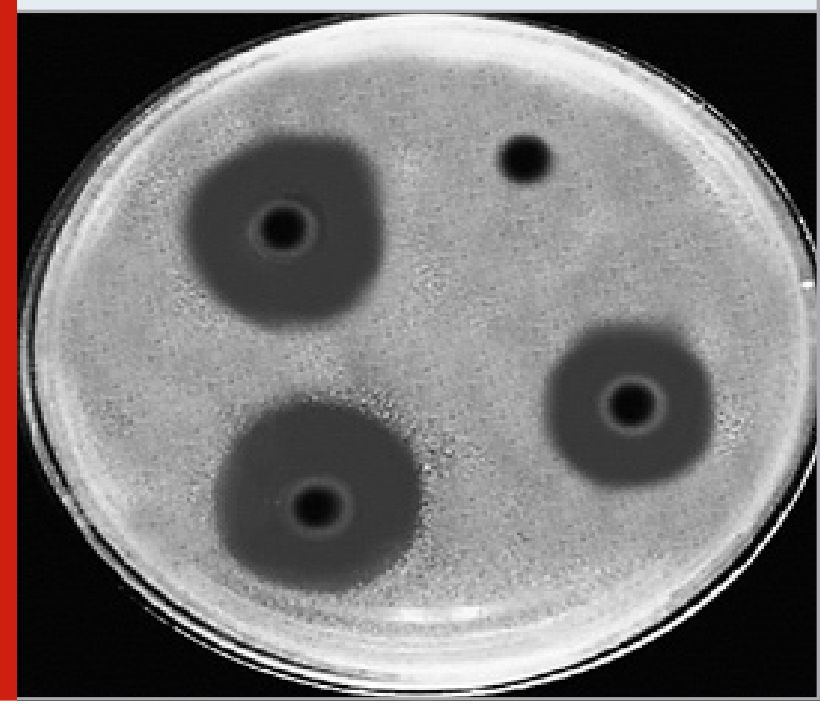

1-Negative control; 2-DS(7.5mM);3- DS(10.0mM); 4$\mathrm{Ca}(\mathrm{OH}) 2$

Statistical analysis: Results were expressed as mean \pm SD. Statistical significance was determined by one-way analysis of variance (ANOVA) using SPSS software (version22.0) and post hoc least significant difference test. $\mathrm{P}$ values less than 0.05 were considered significant.

\section{RESULT AND DISCUSSION}

Table 1: The table shows the mean minimum inhibitory concentration (C. albicans) of the negative control group, various concentrations of Diclofenac Sodium and Calcium hydroxide.

Table 1

\begin{tabular}{|l|c|c|c|}
\hline GROUPS & Mean & $\mathrm{N}$ & $\begin{array}{c}\text { Std. } \\
\text { Deviation }\end{array}$ \\
\hline NEGATIVE CONTROL & .512 & 3 & .04 \\
\hline $\begin{array}{l}\text { DICLOFENAC SODIUM } \\
\text { [1 mM/ML] }\end{array}$ & .494 & 3 & .04 \\
\hline $\begin{array}{l}\text { DICLOFENAC SODIUM } \\
\text { [2.5 mM/ML] }\end{array}$ & .399 & 3 & .03 \\
\hline $\begin{array}{l}\text { DICLOFENAC SODIUM } \\
\text { [5 mM/ML] }\end{array}$ & .301 & 3 & .02 \\
\hline $\begin{array}{l}\text { DICLOFENAC SODIUM } \\
\text { [7.5 mM/ML] }\end{array}$ & .215 & 3 & .01 \\
\hline $\begin{array}{l}\text { DICLOFENAC SODIUM } \\
{[10 \mathrm{mM} / \mathrm{ML}]}\end{array}$ & .104 & 3 & .01 \\
\hline $\begin{array}{l}\text { CALCIUM HYDROXIDE } \\
\text { Total }\end{array}$ & .098 & 3 & .02 \\
\hline
\end{tabular}


The mean values of different concentrations of diclofenac sodium, calcium hydroxide and negative control are taken and minimum inhibitory concentration and minimum fungicidal concentrations values are obtained (Table 1 \& Table 2). The results indicate that at a minimum inhibitory concentration of diclofenac sodium at $2.5 \mathrm{mM} /$ $\mathrm{ml}$, the percentage of microbial growth inhibition of diclofenac sodium is lesser than calcium hydroxide (Figure 4) and the minimum fungicidal concentration was $7.5 \mathrm{mM} / \mathrm{ml}$ (Figure 5). Kristiansen and Amaral (1997) were paramount in bringing research into antibacterial activity of "nonantibiotics," Non antibiotics are those that not only treat noninfectious diseases but also exhibit antimicrobial activity. The application of diclofenac sodium either intracanal or systemic application has shown to alleviate postoperative endodontic pain (Blanscet et al., 2008; Young et al., 2007) Diclofenac sodium has exhibited antimicrobial effect against both gram-positive and gram-negative bacteria (Dastidar et al., 2000) and also exhibited synergism with other antibiotics (Mazumdar et al., 2009) These studies have proven that diclofenac is a potent non-antibiotic antibacterial agent. But the doubt arises if diclofenac sodium is compatible as an antimicrobial agent in systemic or intracanal usage in endodontics with simultaneous anti-inflammatory and pain management effects. In an in vitro study conducted by Salem Malini et al, antibacterial effect of Diclofenac sodium was tested against an endodontic pathogenic E. faecalis (Salem-Milani et al., 2013)

Figure 4: Bar chart depicts the Minimal Inhibitory Concentration of all groups. "denotes all test groups resulted better than the negative control group $(\mathrm{p}<0.05)$, "a" denotes Calcium hydroxide and Diclofenac Sodium $(10 \mathrm{mM} / \mathrm{ml})$ were better when compared to other groups $(p<0.05)$. No significant difference seen between calcium hydroxide and Diclofenac Sodium $(10 \mathrm{mM} / \mathrm{ml})$. The minimum inhibitory concentration of Diclofenac sodium was found to be $2.5 \mathrm{mM} / \mathrm{ml}$

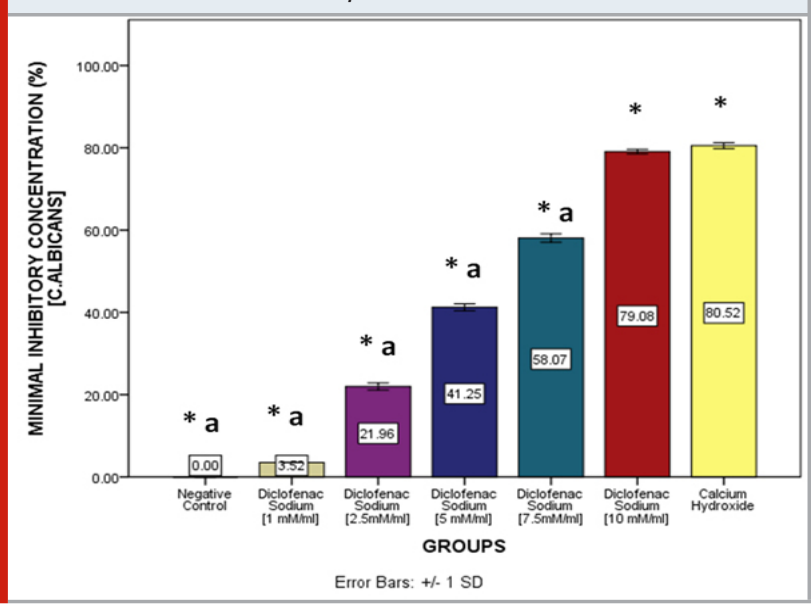

Diclofenac sodium has been used in the management of post endodontic pain over a period of time. It is known to alleviate the pain post endodontic treatment when it is administered preoperatively(Negm, 1994; Saatchi et al., 2009) There are certain potential advantages of using NSAIDs as intracanal medicament which are stated as follows: anti-inflammatory action, local analgesic action and possible antimicrobial action. Domenico et al was probably the first to conduct a research into the antimicrobial efficacy of NSAIDs (Domenico et al., 1989) In the in vitro and in vivo animal studies conducted by Annadurai et al, Dastidar et al, Dutta et al, they revealed that Diclofenac sodium exhibited antibacterial efficacy against Salmonella typhimurium, Mycobacterium tuberculosis and Listeria monocytogenes (Dutta et al., 2008; Dutta, Mazumdar, et al., 2007)

Table 2. The table shows the mean values of minimum fungicidal concentrations of the control group, various concentrations of Diclofenac Sodium and Calcium hydroxide.NI means no inhibition zone. Each value is expressed as mean \pm SD $(n=3)$

\begin{tabular}{|l|c|c|}
\hline Samples & Conc (mM) & $\begin{array}{c}\text { C. albicans } \\
\text { Zone of } \\
\text { Inhibition(mm) } \\
\text { (Mean } \pm \text { SD) }\end{array}$ \\
\hline Negative control & - & NI \\
\hline DS & 7.5 & $8.1 \pm 0.75$ \\
\hline DS & 10.0 & $9.4 \pm 0.92$ \\
\hline Ca $(\mathrm{OH})_{2}$ & & $13.5 \pm 1.1$ \\
\hline
\end{tabular}

Figure 5: The graph depicts the minimum fungicidal concentration of the negative control group,Diclofenac Sodium at two different concentrations $(7.5 \mathrm{mM} / \mathrm{ml}, 10$ $\mathrm{mM} / \mathrm{ml}$ ) and the calcium hydroxide group. "denotes all the test groups performed better than the negative control group $(\mathrm{p}<0.01)$. "a" denotes $\mathrm{p}<0.001$ as compared with Ca. $(\mathrm{OH}) 2$.The minimum fungicidal concentration is found to be $7.5 \mathrm{mM} / \mathrm{ml}$

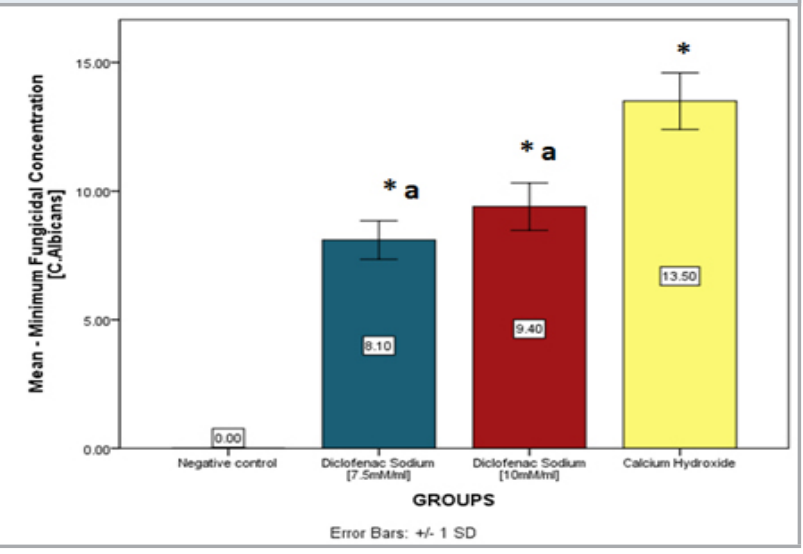

The exact mechanism of antimicrobial activity of diclofenac remains unclarified. Few studies have proposed following mechanisms:Inhibition of bacterial DNA synthesis (Silva et al., 2018), Impairment of cell membrane activity, Anti Plasmid activity, Reduced quorum sensing leading to decreased biofilm formation (Chockattu et al., 2018; Dutta, Annadurai, et al., 2007) In this study, the antimicrobial activity of Diclofenac 
sodium as an intracanal medicament was tested against Candida albicans strain. Its efficacy was compared with the standard and most commonly used intracanal medicament Calcium hydroxide. The reason to select Candida albicans is based on the studies that showed the presence of these microorganisms in refractory infections after endodontic treatment. The minimum inhibitory concentration at which the fungal growth was suppressed at $2.5 \mathrm{mM} / \mathrm{ml}$. It is less compared to calcium hydroxide's efficacy but not in significant amounts. The minimum fungicidal concentration determined on agar well diffusion assay also showed that calcium hydroxide has a little higher fungicidal activity compared to Diclofenac sodium.

Some studies have shown that inclusion of diclofenac sodium in the intra canal dressings managed to alleviate the inter appointment pain (Dutta et al., 2004)However, few studies have shown the antibacterial efficacy of diclofenac sodium mainly against bacteria such as E.faecalis (Salem-Milani et al., 2013) The results of those studies have proposed that theoretically diclofenac sodium can act as a substitute for calcium hydroxide. But however, the results of those studies should be interpreted with caution and further studies should be conducted to evaluate the exact efficacy of diclofenac sodium (Padma and Yalavarthy, 2015) The exact mechanism of action of diclofenac sodium is unclear. Few studies have mentioned it may be due to the inhibition of microbial DNA synthesis or impairment of membrane activity or impairment of plasmid activity (Chockattu et al., 2018)

Agar well diffusion assay is a simple, rapid and well standardized traditional method for testing of antimicrobial efficacy. It is most commonly used by all the clinical laboratories because of its minimal equipment, cost effectiveness and readily accessible supplies (Balouiri et al., 2016) Umpteen variety of materials can be tested quickly by using this method. However, the accuracy of the results should be contemplated as there are chances of false results (Chen et al., 2019) For example, the inhibition zone does not always have regular boundaries because it can be influenced by factors such as diffusion rates of materials through agar, concentration and solubility of various antimicrobials (Besra and Kumar, 2018) Besides, the determination of MIC by tube dilution method in vitro may not reflect the ideal conditions in vivo as in in vivo there will be a complex biofilm instead of a single strain (Hiremath et al., 2015) Hence, further studies should be conducted to precisely determine the antimicrobial efficiency of diclofenac sodium.

\section{CONCLUSION}

Minimal inhibitory concentration is used to evaluate the antimicrobial efficacy of various compounds by measuring the effect of decreasing concentrations of the compound over a defined time period in terms of inhibition of microbial growth. These evaluations can be useful to determine the final concentration of the antimicrobial compound. MFC is complementary to MIC where it identifies the lowest concentration of antimicrobial agent that reduces the viability of fungal inoculum and denoting the microbial death. These testings are good and relatively inexpensive to simultaneously evaluate multiple antimicrobial agents for efficacy.Within the limitations of the study, it has been noticed that diclofenac sodium has some fungicidal activity but less when compared to calcium hydroxide.

\section{ACKNOWLEDGEMENTS}

We would like to thank all my staff members and peers for their constant support and encouragement

\section{Conflicts of Interest: Nil}

\section{REFERENCES}

Azeem RA and Sureshbabu NM (2018) Clinical performance of direct versus indirect composite restorations in posterior teeth: A systematic review. Journal of conservative dentistry: JCD 21(1): 2-9.

Balouiri M, Sadiki M and Ibnsouda SK (2016) Methods for in vitro evaluating antimicrobial activity: A review. Journal of pharmaceutical analysis 6(2): 71-79.

Besra M and Kumar V (2018) In vitro investigation of antimicrobial activities of ethnomedicinal plants against dental caries pathogens. 3 Biotech 8(5): 257.

Blanscet ML, Tordik PA and Goodell GG (2008) An agar diffusion comparison of the antimicrobial effect of calcium hydroxide at five different concentrations with three different vehicles. Journal of endodontia 34(10): 1246-1248.

Chen C-C, Lai C-C, Huang H-L, et al. (2019) Antimicrobial Activity of Lactobacillus Species Against CarbapenemResistant Enterobacteriaceae. Frontiers in microbiology 10: 789.

Chockattu SJ, Deepak BS and Goud KM (2018) Comparison of anti-bacterial efficiency of ibuprofen, diclofenac, and calcium hydroxide against Enterococcus faecalis in an endodontic model: An in vitro study. Journal of conservative dentistry: JCD 21(1): 80-84.

Dastidar SG, Ganguly K, Chaudhuri K, et al. (2000) The anti-bacterial action of diclofenac shown by inhibition of DNA synthesis. International journal of antimicrobial agents 14(3): 249-251.

Domenico P, Schwartz S and Cunha BA (1989) Reduction of capsular polysaccharide production in Klebsiella pneumoniae by sodium salicylate. Infection and immunity 57(12): 3778-3782.

Dutta NK, Kumar KA, Mazumdar K, et al. (2004) In vitro and in vivo antimycobacterial activity of antiinflammatory drug, diclofenac sodium. Indian journal of experimental biology 42(9): 922-927.

Dutta NK, Mazumdar K, Dastidar SG, et al. (2007) Activity of diclofenac used alone and in combination with streptomycin against Mycobacterium tuberculosis 
in mice. International journal of antimicrobial agents 30(4): 336-340.

Dutta NK, Annadurai S, Mazumdar K, et al. (2007) Potential management of resistant microbial infections with a novel non-antibiotic: the anti-inflammatory drug diclofenac sodium. International journal of antimicrobial agents 30(3): 242-249.

Dutta NK, Mazumdar K, Baek MW, et al. (2008) In vitro efficacy of diclofenac against Listeria monocytogenes. European journal of clinical microbiology $\&$ infectious diseases: official publication of the European Society of Clinical Microbiology 27(4): 315-319.

Govindaraju L, Neelakantan P and Gutmann JL (2017) Effect of root canal irrigating solutions on the compressive strength of tricalcium silicate cements. Clinical oral investigations 21(2): 567-571.

Hiremath G, Kulkarni R and Naik B (2015) Evaluation of minimal inhibitory concentration of two new materials using tube dilution method: An in vitro study. Journal of Conservative Dentistry. DOI: 10.4103/09720707.153056.

Janani K and Sandhya R (2019) A survey on skills for cone beam computed tomography interpretation among endodontists for endodontic treatment procedure. Indian journal of dental research: official publication of Indian Society for Dental Research 30(6): 834-838.

Jenarthanan S and Subbarao C (2018) Comparative evaluation of the efficacy of diclofenac sodium administered using different delivery routes in the management of endodontic pain: A randomized controlled clinical trial. Journal of conservative dentistry: JCD 21(3): 297-301.

Khandelwal A and Palanivelu A (2019) Correlation Between Dental Caries And Salivary Albumin In Adult Population In Chennai: An In Vivo Study. Brazilian Dental Science 22(2): 228-233.

Kim D and Kim E (2014) Antimicrobial effect of calcium hydroxide as an intracanal medicament in root canal treatment: a literature review - Part I. In vitro studies. Restorative dentistry \&t endodontics 39(4): 241-252.

Kim D and Kim E (2015) Antimicrobial effect of calcium hydroxide as an intracanal medicament in root canal treatment: a literature review - Part II. in vivo studies. Restorative dentistry \&t endodontics 40(2): 97-103.

Kristiansen J (1997) The potential management of resistant infections with non-antibiotics. Journal of Antimicrobial Chemotherapy. DOI: 10.1093/ jac/40.3.319.

Malli Sureshbabu N, Selvarasu K, V JK, et al. (2019) Concentrated Growth Factors as an Ingenious Biomaterial in Regeneration of Bony Defects after Periapical Surgery: A Report of Two Cases. Case reports in dentistry 2019: 7046203.
Manohar MP and Sharma S (2018) A survey of the knowledge, attitude, and awareness about the principal choice of intracanal medicaments among the general dental practitioners and nonendodontic specialists. Indian journal of dental research: official publication of Indian Society for Dental Research 29(6): 716-720. Mazumdar K, Dastidar SG, Park JH, et al. (2009) The anti-inflammatory non-antibiotic helper compound diclofenac: an antibacterial drug target. European journal of clinical microbiology \& infectious diseases: official publication of the European Society of Clinical Microbiology 28(8): 881-891.

Nandakumar M and Nasim I (2018) Comparative evaluation of grape seed and cranberry extracts in preventing enamel erosion: An optical emission spectrometric analysis. Journal of conservative dentistry: JCD 21(5): 516-520.

Narayanan LL and Vaishnavi C (2010) Endodontic microbiology. Journal of conservative dentistry: JCD 13(4): 233-239.

Negm MM (1994) Effect of intracanal use of nonsteroidal anti-inflammatory agents on posttreatment endodontic pain. Oral surgery, oral medicine, and oral pathology 77(5): 507-513.

Padma R and Yalavarthy PD (2015) Screening of diclofenac for antibacterial activity against pathogenic microorganisms. Int. J. Adv. Pharm. Biol. Chem 4(3): 554-558.

Poorni S, Srinivasan MR and Nivedhitha MS (2019) Probiotic strains in caries prevention: A systematic review. Journal of conservative dentistry: JCD 22(2): 123-128.

Rajakeerthi R and Ms N (2019) Natural Product as the Storage medium for an avulsed tooth - A Systematic Review. Cumhuriyet Dental Journal 22(2): 249-256.

Rajendran R, Kunjusankaran RN, Sandhya R, et al. (2019) Comparative Evaluation of Remineralizing Potential of a Paste Containing Bioactive Glass and a Topical Cream Containing Casein Phosphopeptide-Amorphous Calcium Phosphate: An in Vitro Study. Pesquisa brasileira em odontopediatria e clinica integrada 19(1): 1-10.

Ramarao S and Sathyanarayanan U (2019) CRA Grid - A preliminary development and calibration of a paper-based objectivization of caries risk assessment in undergraduate dental education. Journal of conservative dentistry: JCD 22(2): 185-190.

Saatchi M, Mosavat F, Razmara F, et al. (2009) Comparison of the effect of Ibuprofen and slow-released Diclofenac Sodium in controlling post endodontic pain. The Journal of dental medicine 22(4). Available at: https://bit.ly/2CExssS.

Salem-Milani A, Balaei-Gajan E, Rahimi S, et al. (2013) Antibacterial Effect of Diclofenac Sodium on 
Enterococcus faecalis. Journal of dentistry 10(1): 16-22.

Siddique R and Nivedhitha MS (2019) Effectiveness of rotary and reciprocating systems on microbial reduction: A systematic review. Journal of conservative dentistry: JCD 22(2): 114-122.

Siddique R, Sureshbabu NM, Somasundaram J, et al. (2019) Qualitative and quantitative analysis of precipitate formation following interaction of chlorhexidine with sodium hypochlorite, neem, and tulsi. Journal of conservative dentistry: JCD 22(1): 40-47.

Siddique R, Nivedhitha MS and Jacob B (2019) Quantitative analysis for detection of toxic elements in various irrigants, their combination (precipitate), and para-chloroaniline: An inductively coupled plasma mass spectrometry study. Journal of conservative dentistry:
JCD 22(4): 344-350.

Silva AA de L e., de Lima e Silva AA and Silva PM (2018) Non-Antibiotic Compounds: The Activity of the NSAID Diclofenac on Bacteria- A Review. International Journal of Current Microbiology and Applied Sciences. DOI: 10.20546/ijcmas.2018.712.042.

Teja KV, Ramesh S and Priya V (2018) Regulation of matrix metalloproteinase-3 gene expression in inflammation: A molecular study. Journal of conservative dentistry: JCD 21(6): 592-596.

Young GR, Parashos P and Messer HH (2007) The principles of techniques for cleaning root canals. Australian dental journal 52(1 Suppl): S52-63.

Zimmermann P and Curtis N (2017) Antimicrobial Effects of Antipyretics. Antimicrobial agents and chemotherapy 61(4). DOI: 10.1128/AAC.02268-16. 